\title{
Experimental Evaluation of Oxide Nanoparticles as Friction and Wear Improvement Additives in Motor Oil
}

\author{
Nicholaos G. Demas, Robert A. Erck, Cinta Lorenzo-Martin, \\ Oyelayo O. Ajayi, and George R. Fenske \\ Argonne National Laboratory, ES 212, 9700 South Cass Ave., Argonne, IL 60439, USA \\ Correspondence should be addressed to Nicholaos G. Demas; ndemas@anl.gov
}

Received 16 October 2016; Revised 21 December 2016; Accepted 4 January 2017; Published 30 January 2017

Academic Editor: Simo-Pekka Hannula

Copyright (C) 2017 Nicholaos G. Demas et al. This is an open access article distributed under the Creative Commons Attribution License, which permits unrestricted use, distribution, and reproduction in any medium, provided the original work is properly cited.

\begin{abstract}
The effect of two nanoparticle oxides on friction and wear was studied under laboratory test conditions using a reciprocating test machine and two test configurations. The addition of these nanoparticles in base stock oil under certain conditions reduced the coefficient of friction and improved wear, but that depended on the test configuration. Examination of the rubbed surfaces showed the pronounced formation of a tribofilm in some cases, while polishing on the surface was also observed in other cases. Contact configuration is important when oxide nanoparticles are being evaluated and the conclusions about their efficacy can be vastly different.
\end{abstract}

\section{Introduction}

Fuel economy improvement and lower emissions are major goals of the automotive industry and are driven, in part, by regulation and, in part, by market forces. With the introduction of low-viscosity oils, component surfaces operate more in the boundary and/or mixed lubrication regimes, and wear can become accelerated.

In recent years, nanoparticles have been considered as friction modifiers and antiwear additives [1-12]. Studies have shown that the addition of nanoparticles to base stock lubricating oil can reduce friction and wear and have concluded that nanoparticles might be beneficial lubricant additives, even though some might be hard and could be abrasive [1, 2, 4-10]. Various hypotheses have been offered about how nanoparticles reduce friction and wear. These include the ball-bearing or rolling effect [2], the formation and removal of layered-structure protective tribofilms [3], penetration into the rubbing surfaces that, in turn, changes the material properties at the contact points between mating surfaces (the "mending effect") [13], and the polishing effect [2]. Most of the evidence found in the open literature was collected from tests performed under laboratory conditions and may not indicate whether the benefits will occur under conditions experienced in an actual engine. For example, contact configurations such as the ball-on-flat, pin-on-flat, four-ball, cylinder-on-flat, and block-on-ring have been used to evaluate oils containing nanoparticles. The use of these test configurations is widespread due to their simplicity, low cost, and the availability of standard samples.

Most laboratory-scale test rigs are limited in their ability to simulate actual engine conditions. Useful information can be extracted as long as prototypical materials are used, and there is some agreement between loads, speeds, temperatures, contact pressures, and surface parameters. In this work, the effect on friction and wear of two nanoparticle oxides $\left(\mathrm{TiO}_{2}\right.$ and $\mathrm{Al}_{2} \mathrm{O}_{3}$ ) dispersed in a lubricant was determined under laboratory test conditions using reciprocating motion and two test configurations (52100 steel ball-on-52100 steel flat and PVD CrN ring-on-gray cast iron liner) at speeds up to $5 \mathrm{~Hz}$ and temperature of $100^{\circ} \mathrm{C}$. The results indicate that the nanoparticle additives tested under ball-on-flat conditions can improve the friction and wear of a base stock oil but can have a detrimental effect on the tribological behavior of realistic materials under conditions that simulate an engine environment. More importantly, the results show that very different results are obtained for different contact configurations. 


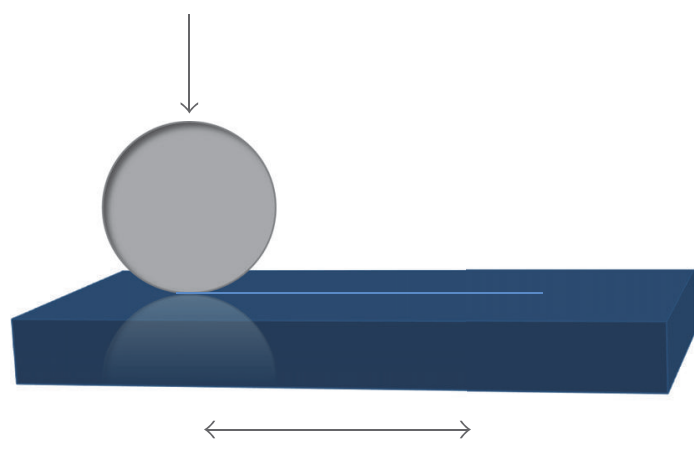

(a)

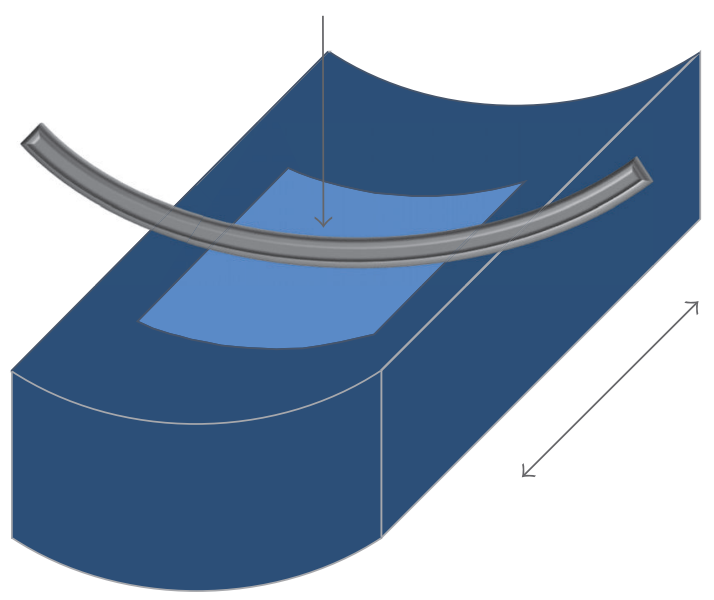

(b)

FIGURE 1: Schematics of contact configurations used in this work: (a) reciprocating ball-on-flat and (b) reciprocating ring-on-liner.

\section{Experimental Procedure}

Experiments were performed with ball-on-flat and ring-onliner specimens in reciprocating motion. The ball-on-flat configuration used 52100 steel counterfaces and $12.7 \mathrm{~mm}(1 / 2$ in.) diameter balls (Grade 25) sliding against mirror-polished flats $\left(S_{q}=10 \mathrm{~nm}\right)$. The load of $15.6 \mathrm{~N}$ produced an initial peak Hertzian contact pressure of $1 \mathrm{GPa}$. The ring-on-liner configuration used specimens extracted from components of a commercial heavy-duty diesel engine. Schematics for the two contact configurations are shown in Figure 1.

The liners were gray cast iron with a typical honing pattern, and the ring was steel that had been coated with CrN by physical vapor deposition (PVD). Figures 2(a) and 2(b) show profilometric images of the cylinder liner and top compression ring surfaces, respectively, with surface parameters given in Table 1. The curvature of the ring was adjusted so that a Hertzian contact width of $10 \mathrm{~mm}$ was achieved. A load of $200 \mathrm{~N}$ produced a contact pressure of approximately $110 \mathrm{MPa}$, which is similar to the contact pressure experienced by the top compression ring.

The oil used was Group IV base stock polyalphaolefin (PAO). The nanoparticles were either silane-coated $\mathrm{TiO}_{2}(5-$ $10 \mathrm{~nm}, 99.5 \%$ purity) or gamma- $\mathrm{Al}_{2} \mathrm{O}_{3}(5 \mathrm{~nm}, 99.9 \%$ purity $)$, obtained from SkySpring Nanomaterials, Inc. The morphology of the $\mathrm{TiO}_{2}$ nanopowder was spherical. The $\mathrm{Al}_{2} \mathrm{O}_{3}$ nanopowder had a fibrous morphology. The powders were blended at $1.0 \mathrm{wt} . \%$ into the oil and sonicated before testing. The $\mathrm{Al}_{2} \mathrm{O}_{3}$ nanopowder was first added to oleic acid and then the resulting solution was added to $\mathrm{PAO}$ while the colloid was mixed using a magnetic stirrer. A fully formulated Group IV 5W30 oil was used for comparison with the rest of the oils.

A small amount of oil $(0.3 \mathrm{~mL})$ was applied at the interface of the test components to create a thin layer at the start of each test. There was no additional lubricant added. This amount of oil was sufficient to last for the entire duration of the
TABLE 1: Surface parameters of the samples used in this work.

\begin{tabular}{lcc}
\hline & Liner & PVD CrN Ring \\
\hline Surface arithmetic roughness $S_{a}(\mu \mathrm{m})$ & 0.468 & 0.288 \\
Surface RMS roughness $S_{q}(\mu \mathrm{m})$ & 0.677 & 0.402 \\
Skewness & -2.132 & -0.762 \\
Kurtosis & 8.606 & 6.270 \\
Maximum peak height $S_{p}(\mu \mathrm{m})$ & 2.247 & 5.290 \\
Maximum valley depth $S_{v}(\mu \mathrm{m})$ & -4.565 & -3.223 \\
Maximum height $S_{z}(\mu \mathrm{m})$ & 6.812 & 8.513 \\
\hline
\end{tabular}

test. This is common practice among different tribotesting laboratories. Lubricant is always available in the contact during testing because, at these temperatures, the rate of oil evaporation is slow. The tests were conducted at $1 \mathrm{~Hz}$ reciprocating frequency for 1 hour using a stroke length of $20 \mathrm{~mm}$. Tests were performed at $100^{\circ} \mathrm{C}$.

The wear tracks on the flats and cylinder liners after the tests were examined with an Olympus STM6 optical microscope and an FEI Quanta 400F scanning electron microscope (SEM) with energy dispersive X-ray spectroscopy (EDX) capability.

An interferometric noncontact optical profilometer (Bruker ${ }^{\circledR}$, ContourGT-K, San Jose, CA) was used for measuring roughness, finish, and texture of a surface. In order to show the true surface of a tribofilm, the test components were coated with a thin layer of reflective gold prior to examination.

\section{Results}

3.1. Suspension Stability and Viscosity of Lubricants. It is well known that a stable suspension of nanoparticles in oils can be difficult to attain and that material, shape, size, 




(a)

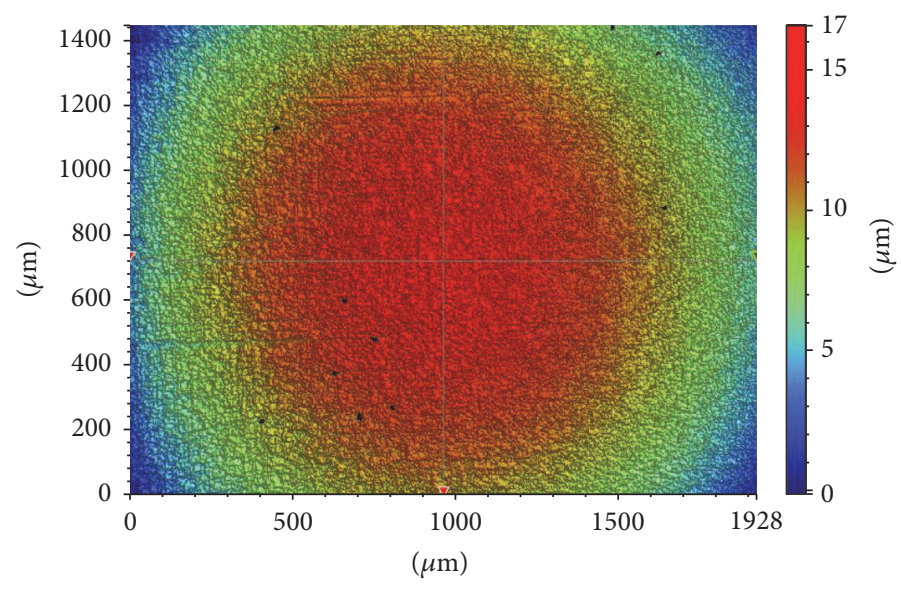

(b)

FIgURE 2: Profilometric images of (a) slide-honed cylinder liner surface and (b) top compression ring surface.

and concentration are important for stability. With time, nanoparticles may agglomerate and settle out of suspension.

The ball-on-flat configuration operates in the boundary regime of sliding (contact between the moving surfaces). Capillary viscosity measurements showed that the addition of the nanopowders used in this work did not change the viscosity of the oil. Friction differences realized between the two test configurations utilized here show boundary coefficients of friction and cannot be attributed to transitions in the lubricating regime.

\subsection{Friction and Wear}

3.2.1. Ball-on-Flat. Graphs of the coefficient of friction as a function of test time for the different lubricants are shown in Figure 3(a). The tests were repeated at least twice and the results were very repeatable. Also graphed is measurement of electrical contact resistance (Figure 3(b)). A small high-impedance voltage was imposed between the samples; open circuit electrical contact resistance indicates electrical separation between the contacts, and zero indicates metalto-metal contact or the formation of a conductive tribofilm. As shown in Figure 3(a), the addition of $\mathrm{TiO}_{2}$ nanoparticles to $\mathrm{PAO}$ reduced the coefficient of friction by approximately
$15 \%$ after a steady-state friction was reached at $1600 \mathrm{~s}$. The addition of $\mathrm{Al}_{2} \mathrm{O}_{3}$ nanoparticles to the $\mathrm{PAO}$ exhibited a very similar behavior. The friction of fully formulated 5W30 oil is superimposed on the plot as a reference. The conventional 5W30 oil gives a friction coefficient approximately $25 \%$ lower than that of the oils containing nanoparticles. A semi-insulating tribochemical film progressively formed in the case of the fully formulated 5W30 oil and the PAO + $\mathrm{Al}_{2} \mathrm{O}_{3}$ oil, as indicated by the electrical contact resistance traces in Figure 3(b). The addition of $\mathrm{TiO}_{2}$ nanoparticles to the PAO also led to the formation of a semi-insulating tribochemical film. The PAO alone formed a conductive film.

Micrographs of the wear scars formed on the balls for each of the formulations are shown in Figure 4. The diameter of the wear scar for PAO (Figure 4(a)) was the largest while the wear scar for the fully formulated 5W30 was the smallest (Figure 4(b)). The addition of both $\mathrm{TiO}_{2}$ and $\mathrm{Al}_{2} \mathrm{O}_{3}$ led to reductions of the wear scar diameter. Figure 5 shows a chart of the amount of ball wear, as measured with an optical profilometer. Very little protection was provided by the base stock oil, but the addition of nanoparticles to the base stock significantly reduced wear. No significant amount of wear occurred in tests using the fully formulated oil. 


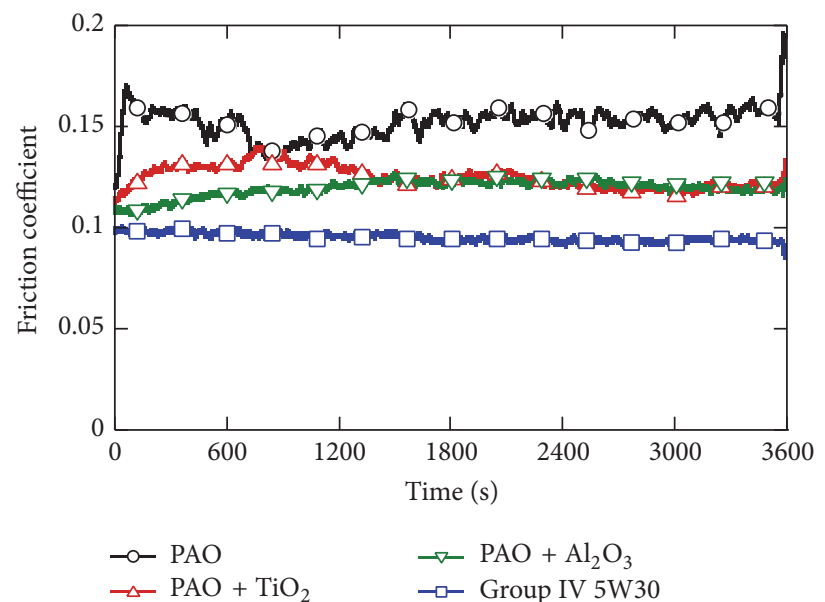

(a)

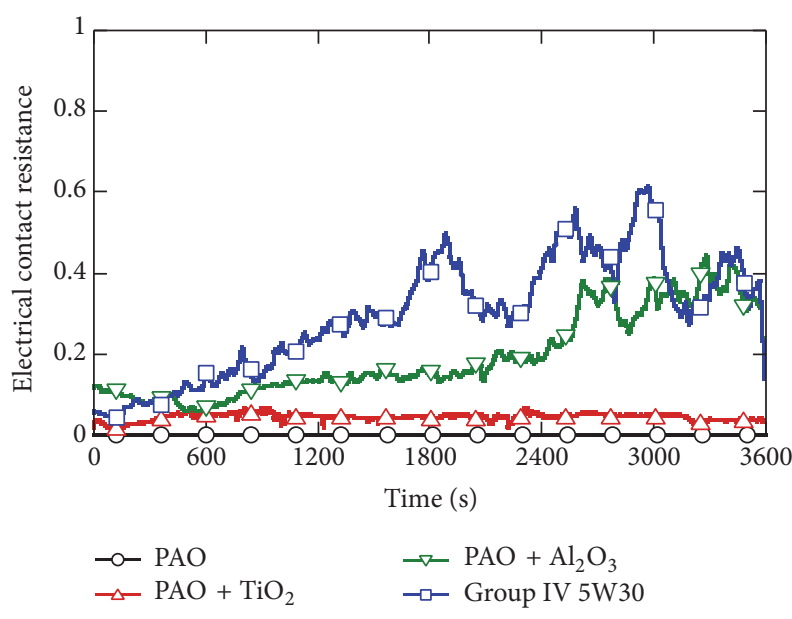

(b)

FIGURE 3: (a) Coefficient of friction and (b) contact resistance traces as a function of time for lubricants tested in this work using the ball-onflat test configuration.



(a)

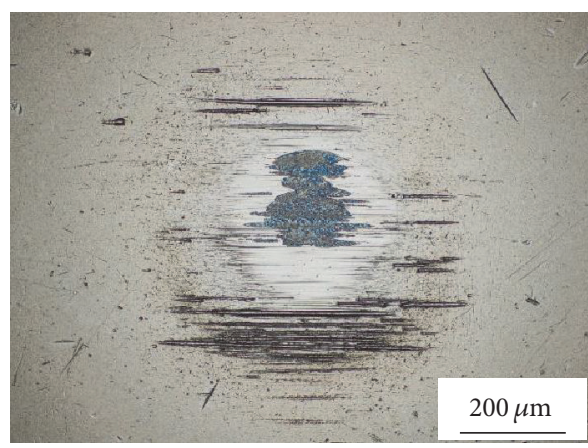

(c)

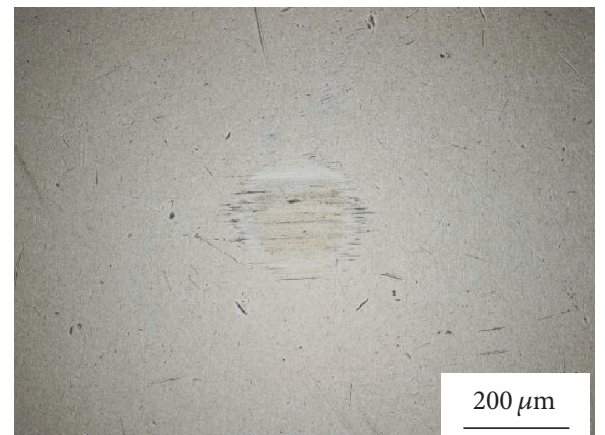

(b)

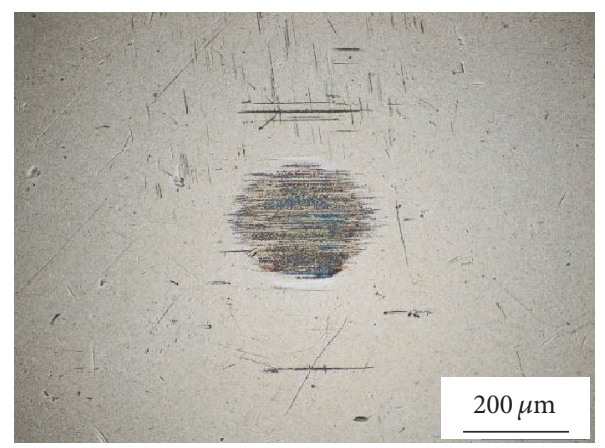

(d)

Figure 4: Optical micrographs of ball wear scars for (a) PAO, (b) fully formulated 5W30, (c) $\mathrm{PAO}+\mathrm{TiO}_{2}$, and (d) $\mathrm{PAO}+\mathrm{Al}_{2} \mathrm{O}_{3}$.

Figure 6 shows optical microscope images of the test tracks on the flat counterface. The test track in the case of the base stock oil had the largest width, while in the case of the fully formulated oil it was the smallest. The tracks for the $\mathrm{Al}_{2} \mathrm{O}_{3}$ - and $\mathrm{TiO}_{2}$-containing lubricants were smaller than PAO alone, and this trend matched well with the scar size on the balls. The formulations produced quite different types of wear. Abrasive marks with the base stock oil are seen in Figure 6(a), while the formation of a brown tribochemical film with the fully formulated 5W30 oil is evident in Figure 6(b). The addition of $\mathrm{TiO}_{2}$ nanoparticles formed a tribofilm with a gray appearance, as shown in Figure 6(c). The addition of $\mathrm{Al}_{2} \mathrm{O}_{3}$ resulted in the formation of a tribofilm with a mostly bright blue appearance.

Line scans across the test tracks were obtained, and the results are shown in Figure 7. Material removal from the test track for sliding in base stock oil occurred as shown in Figure 7(a). The fully formulated oil resulted in the formation 


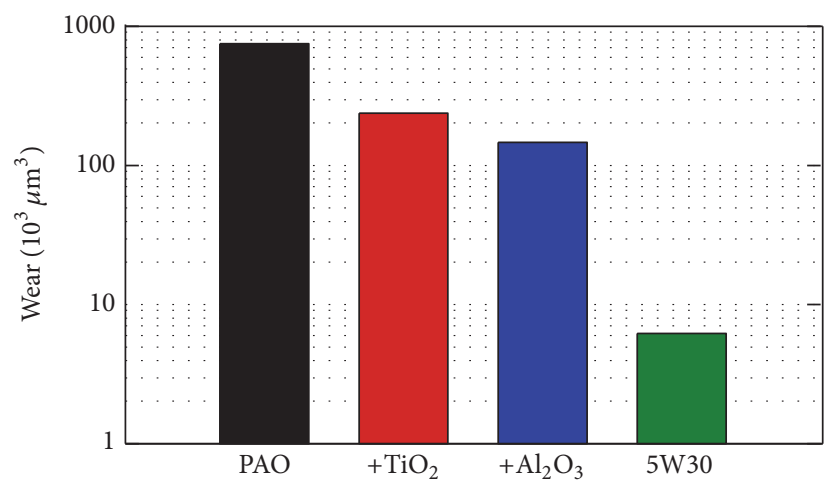

FIGURE 5: Ball wear volume for oils used in this work.

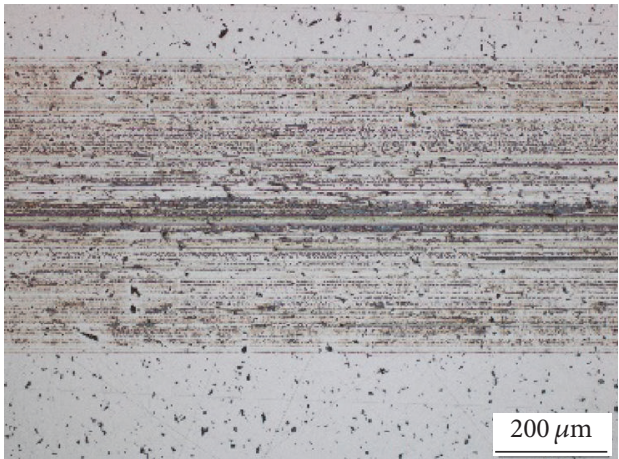

(a)

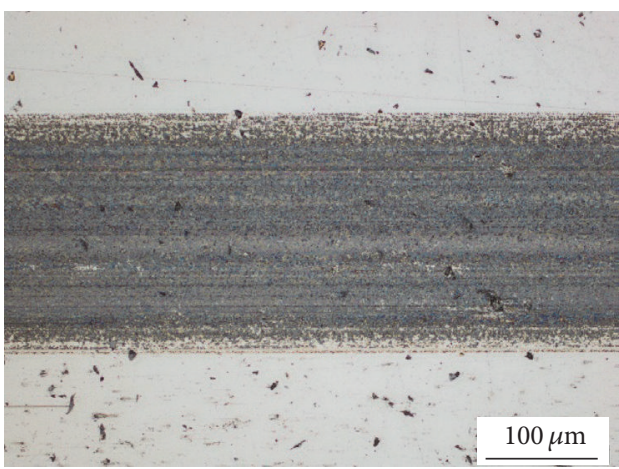

(c)

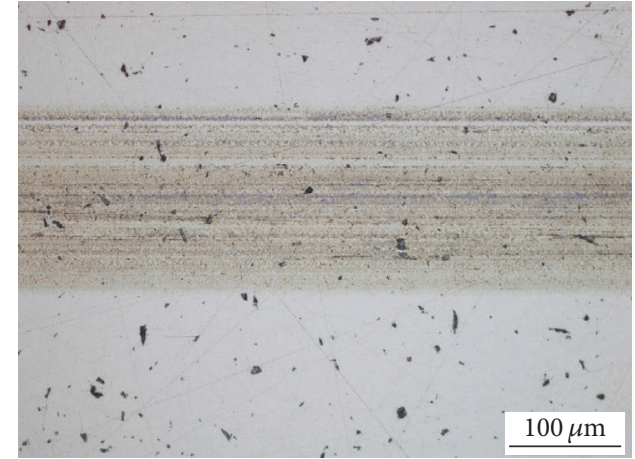

(b)

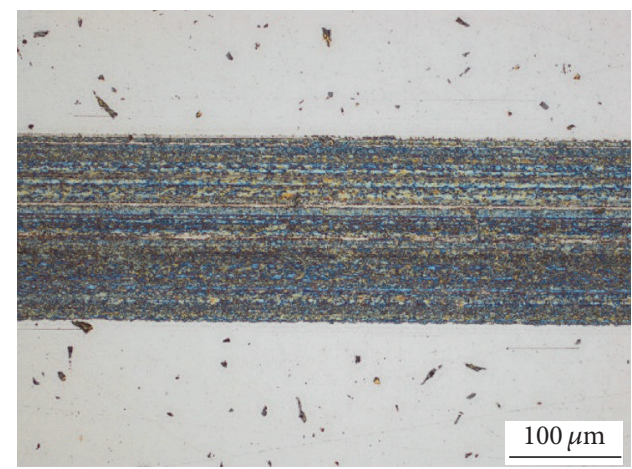

(d)

Figure 6: Optical micrographs of flat test tracks for (a) PAO, (b) fully formulated 5W-30, (c) $\mathrm{PAO}+\mathrm{TiO}_{2}$, and (d) $\mathrm{PAO}+\mathrm{Al}_{2} \mathrm{O}_{3}$.

of tribochemical film with a thickness of approximately $30 \mathrm{~nm}$, as shown in Figure 7(b). The $\mathrm{TiO}_{2}$ nanoparticles produced a tribofilm of approximately $75 \mathrm{~nm}$ thickness, as shown in Figure $7(\mathrm{c})$. The $\mathrm{Al}_{2} \mathrm{O}_{3}$ nanoparticles resulted in roughening of the test track, as shown in Figure 7(d).

3.2.2. Ring-on-Liner. Figure 8 shows the coefficient of friction and electrical contact as a function of test time for the ringon-liner tests with the different lubricants. Unlike the ballon-flat tests, the addition of $\mathrm{TiO}_{2}$ nanoparticles to PAO increased the coefficient of friction, as shown in Figure 8(a). The tests were repeated at least twice and the results were very repeatable. It can also be seen that the coefficient of friction increased during the test, and a steady-state was not reached. The addition of $\mathrm{Al}_{2} \mathrm{O}_{3}$ to $\mathrm{PAO}$ caused no appreciable frictional difference, and a steady-state value similar to the value using base stock was attained. The fully formulated 5W30 oil provided a lower coefficient of friction (near 0.1), similar to the case of the ball-on-flat test. During the ringon-liner test, the electrical resistivity indicated that a semiinsulating film formed for all oil formulations.

Figure 9 shows optical micrographs of the test tracks on the cylinder liner segment near the reversal point. The unrubbed area is shown in each of these as a reference. Unlike the case of the fully formulated oil, where a tribochemical film formed, and base stock oil, where minor scratches can be seen, the addition of nanoparticles caused pitting or denting. 




(a)

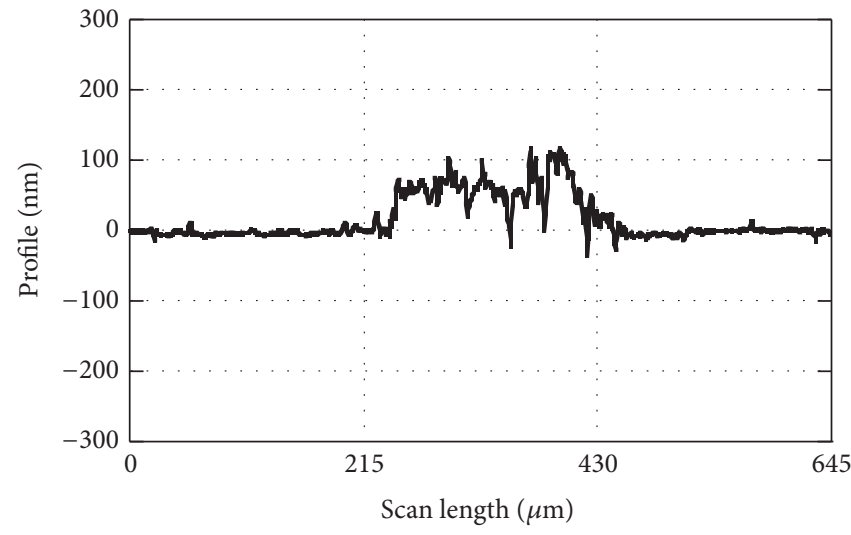

(c)

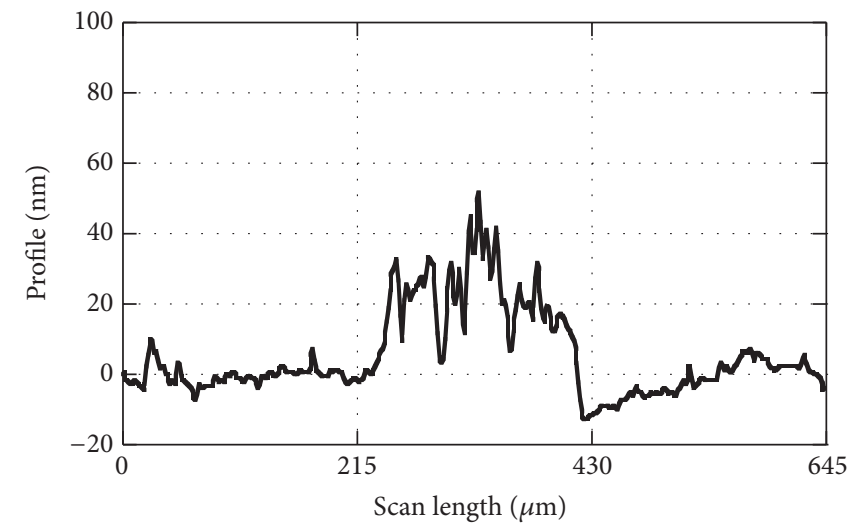

(b)

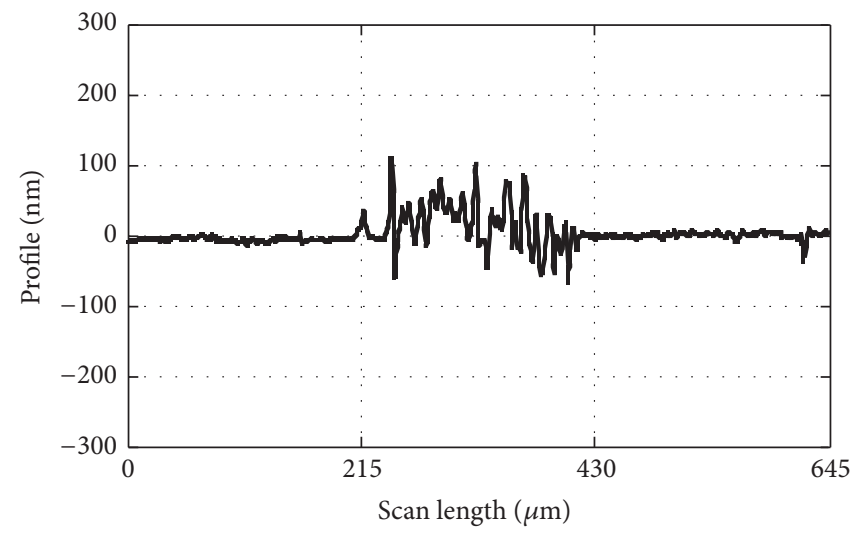

(d)

Figure 7: Profilometric line scans across the flat test track for (a) PAO, (b) fully formulated 5W-30, (c) $\mathrm{PAO}+\mathrm{TiO}_{2}$, and $(\mathrm{d}) \mathrm{PAO}+\mathrm{Al}_{2} \mathrm{O}_{3}$.

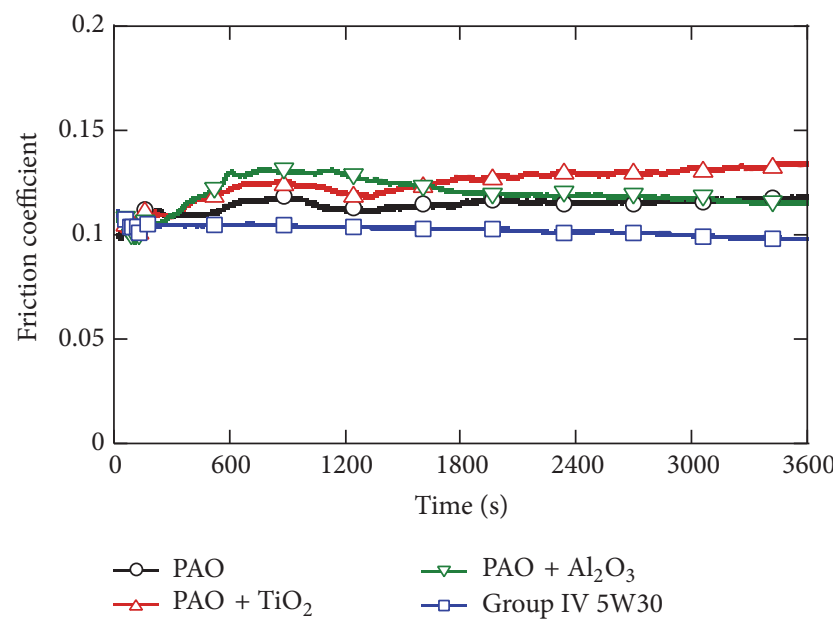

(a)

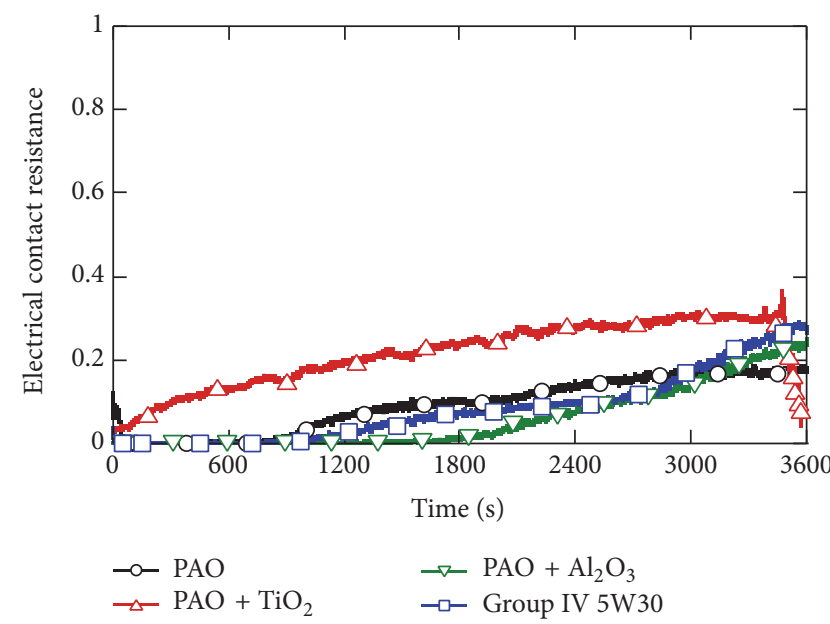

(b)

Figure 8: (a) Coefficient of friction and (b) contact resistance traces as a function of time for lubricants tested in this work using the ringon-liner test configuration.

Figure 10 shows optical profilometric measurements of the wear tracks similar to the micrographs of Figure 9. Mild liner polishing can be seen in the case of base stock. In the case of the fully formulated oil, the formation of a tribofilm on the surface, and in particular at the plateau areas of the honed liner, led to a smoother topography than the original surface. Investigation of regions within the test track clearly showed the presence of pits in the case of $\mathrm{TiO}_{2}$ additive, as shown in Figure $10(\mathrm{c})$. These pits are less evident in the case of $\mathrm{Al}_{2} \mathrm{O}_{3}$ additive where the polishing effect is more pronounced. 




(a)

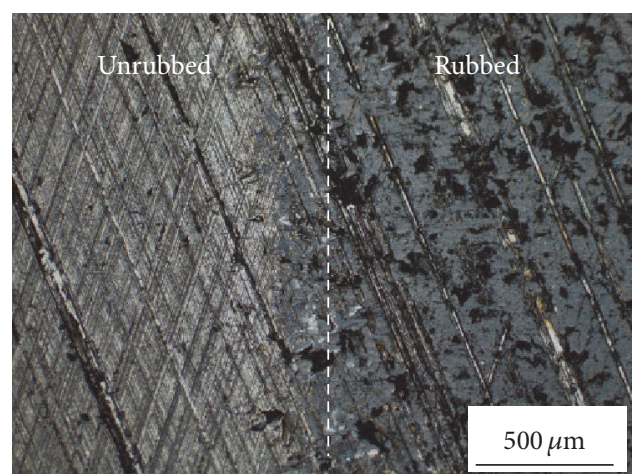

(c)

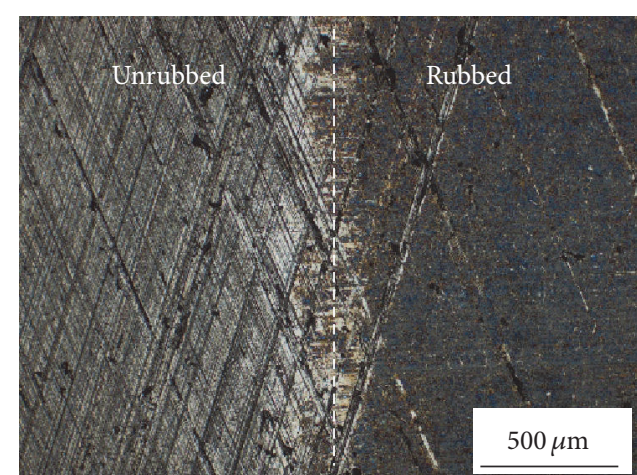

(b)

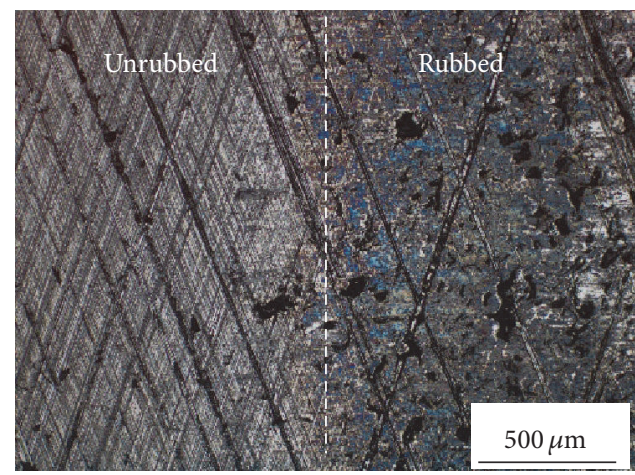

(d)

FIGURE 9: Optical micrographs of test tracks on the cylinder liner segment near the reversal point for Group IV: (a) PAO, (b) fully formulated 5W-30, (c) $\mathrm{PAO}+\mathrm{TiO}_{2}$, and (d) $\mathrm{PAO}+\mathrm{Al}_{2} \mathrm{O}_{3}$.

Optical micrographs of the test scar on the ring are shown in Figure 11. The formation of a tribofilm can be seen on the rubbed areas, but in the case of base stock and fully formulated oil of Figures 11(a) and 11(b), respectively, the test track scars are faint. The addition of $\mathrm{TiO}_{2}$ nanoparticles to base stock oil produced an optically blue tribofilm, while $\mathrm{Al}_{2} \mathrm{O}_{3}$ nanoparticles added to base stock oil resulted in polishing of the ring evident from the formation of a shiny area and limited formation of brown streaks of tribofilm.

Optical profilometry confirmed (Figures 12(a) and 12(b)) that the rings were largely unaffected in the cases of base stock and fully formulated oil. However, the addition of $\mathrm{TiO}_{2}$ and $\mathrm{Al}_{2} \mathrm{O}_{3}$ to base stock oil resulted in polishing (Figures 12 (c) and $12(\mathrm{~d})$ ). The roughness values remained approximately the same as the original roughness of the $\operatorname{ring}\left(S_{a}=100 \mathrm{~nm}\right)$ in the case of PAO and 5W30, as evident in Figures 12(a) and 12(b), respectively, but they decreased to approximately $60 \mathrm{~nm}$ in the case of $\mathrm{PAO}+\mathrm{TiO}_{2}$ and to less than $50 \mathrm{~nm}$ in the case of $\mathrm{PAO}+\mathrm{Al}_{2} \mathrm{O}_{3}$.

\subsection{Energy Dispersive X-Ray Analysis}

3.3.1. Ball-on-Flat. Energy dispersive X-ray (EDX) analysis was performed on all flat test tracks after the surface oil was removed with acetone. Figure 13(a) shows the spectrum inside the flat test track for PAO. On this test track, only Fe peaks were detected. The peaks in Figure 13(b) show the presence of $\mathrm{Fe}$ and several elements attributable to the additives in the fully formulated 5W30 oil (Ca, P or Mo, and $\mathrm{S}$ ). The $\mathrm{P}$ and Mo assignments occur at approximately the same energy, and therefore, the presence of Mo cannot be confirmed. However, that is not of importance for the discussion in this work. As shown in Figure 13(c) for the case of $\mathrm{PAO}+\mathrm{TiO}_{2}$, Ti was present on the surface of the flat inside the test track. In the case of $\mathrm{Al}_{2} \mathrm{O}_{3}$ additive, Figure 13(d) does not show peaks for $\mathrm{Al}$.

3.3.2. Ring-on-Liner. Figure 14(a) shows the EDX spectrum inside the liner test track for PAO. For all lubricants, Fe and Si peaks were detected, which are elements present in the gray cast iron. Figure 14(b) also shows peaks for $\mathrm{Ca}$ and $\mathrm{P}$, which correspond to elements in the chemicals that are added to the fully formulated oil. Figure 14(c) shows that Ti was present on the surface of the liner for the case of $\mathrm{PAO}+\mathrm{TiO}_{2}$. For the case of $\mathrm{Al}_{2} \mathrm{O}_{3}$ additive, Figure 14(d) shows that $\mathrm{Al}$ was detected on the liner test track, indicating the deposition of $\mathrm{Al}_{2} \mathrm{O}_{3}$ on the surface where the rubbing occurred.

\section{Discussion}

The vast majority of tribological performance evaluation of new additives intended for engine applications are conducted with the ball-on-flat configuration. While there is merit to using this configuration in evaluating certain lubricants, it is a contact configuration that cannot not be used to evaluate lubricants containing solid oxide nanoparticles to reveal wear 


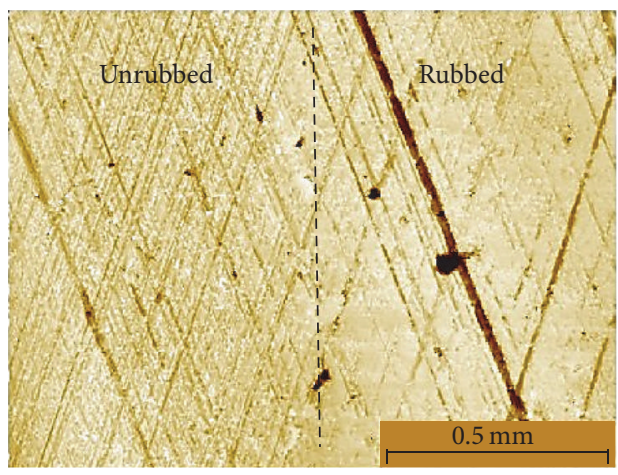

(a)

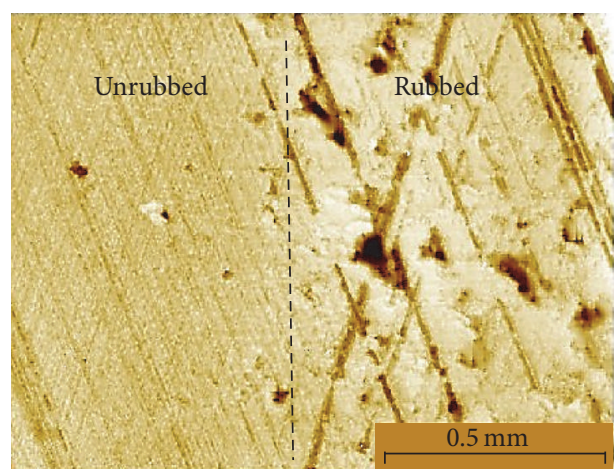

(c)

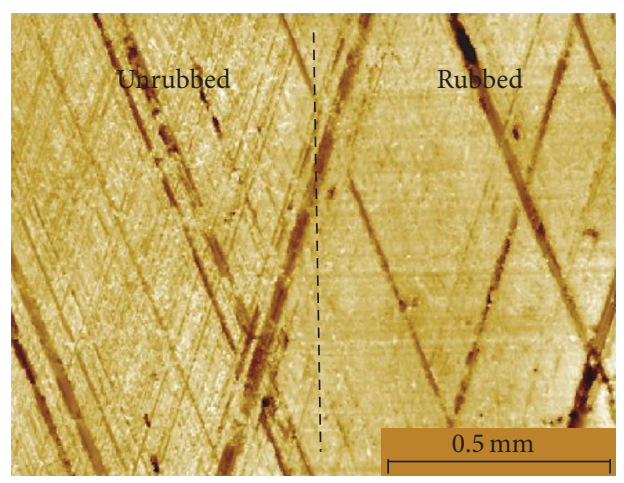

(b)

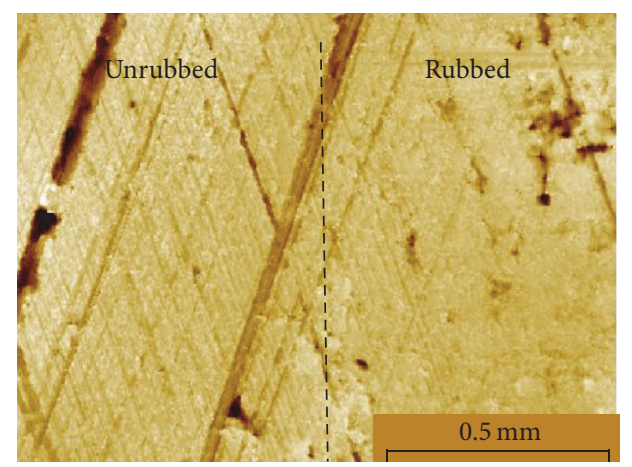

(d)

FIGURE 10: Profilometric images of test tracks on the cylinder liner segment near the reversal point for (a) PAO, (b) fully formulated 5W-30, (c) $\mathrm{PAO}+\mathrm{TiO}_{2}$, and (d) $\mathrm{PAO}+\mathrm{Al}_{2} \mathrm{O}_{3}$.

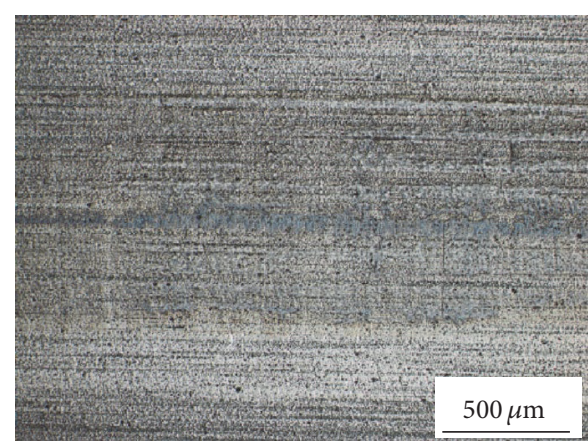

(a)

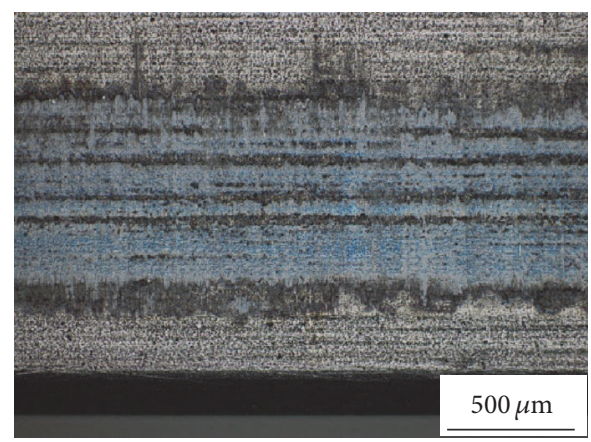

(c)

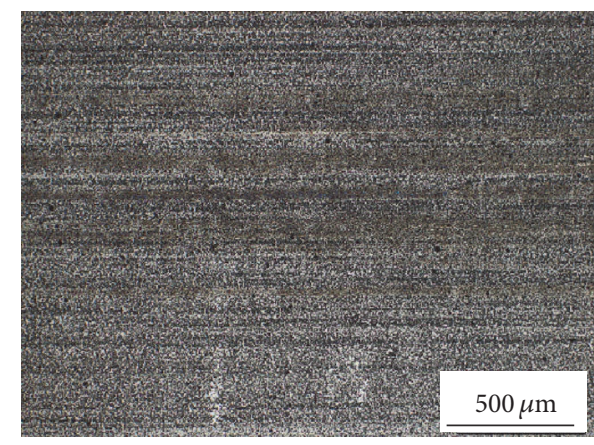

(b)

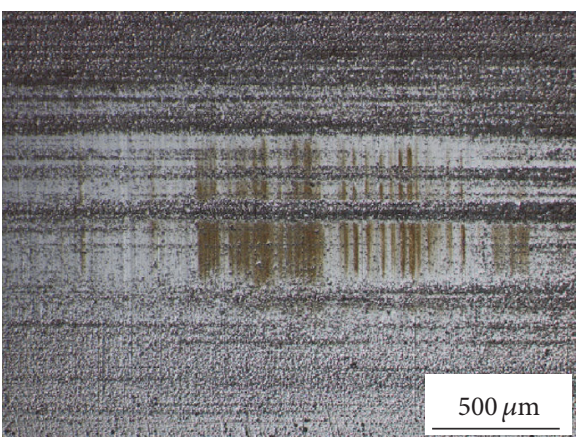

(d)

Figure 11: Optical micrographs of top compression ring test scars for (a) PAO, (b) fully formulated 5W-30, (c) $\mathrm{PAO}+\mathrm{TiO}_{2}$, and (d) PAO + $\mathrm{Al}_{2} \mathrm{O}_{3}$. 


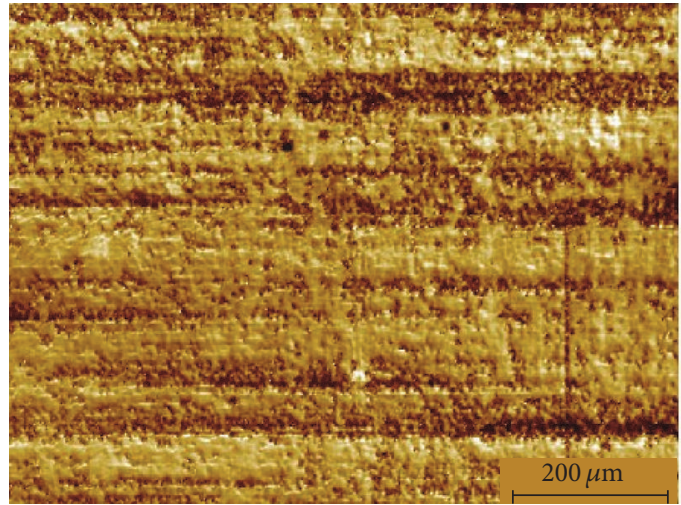

(a)



(c)

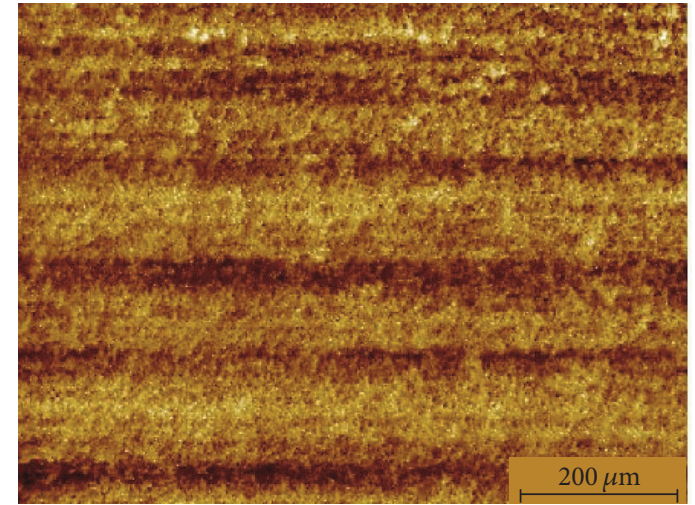

(b)

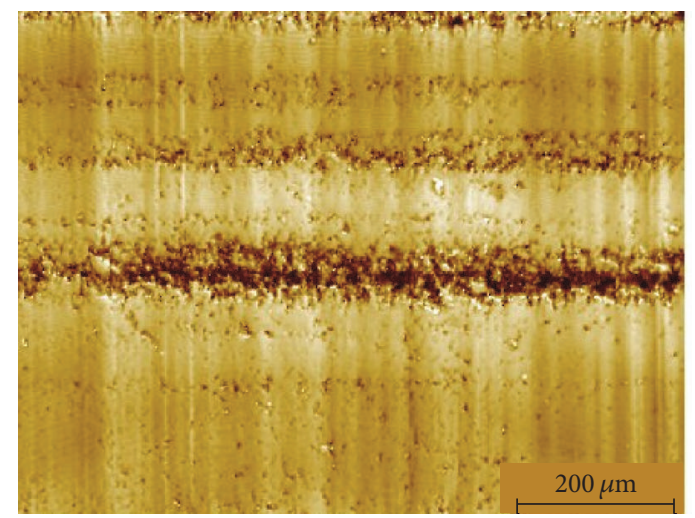

(d)

Figure 12: Profilometric images of top compression ring test scars for (a) PAO, (b) fully formulated 5W-30, (c) $\mathrm{PAO}+\mathrm{TiO}_{2}$, and (d) $\mathrm{PAO}+$ $\mathrm{Al}_{2} \mathrm{O}_{3}$.

mechanisms that would be anticipated when materials with different roughness, composition, and hardness subjected under different contact pressures were used.

From the ball-on-flat test for a fully formulated oil and $\mathrm{PAO}+\mathrm{TiO}_{2}$, it was evident that a positive tribofilm formed on the surfaces. From the ring-on-liner test for the fully formulated oil there was visual evidence as well as EDS analysis that showed the formation of a positive tribofilm on the liner surface and on the ring counterface. However, for the ring-on-liner tests, unlike the case of the fully formulated oil, where a thick tribochemical film formed, and base stock oil, where minor scratches could be seen, the addition of both $\mathrm{TiO}_{2}$ and $\mathrm{Al}_{2} \mathrm{O}_{3}$ nanoparticles caused polishing and pitting, effects that were not captured by the ball-on-flat tests.

In lubrication mechanisms, shearing of the fluid and its content at the contact interface determines the frictional behavior. The fluid is entrained or drawn into the contact interface by the relative motion of the two surfaces. The amount of the fluid (fluid film thickness) in concentrated contact is dependent on viscosity, speed, and to a lesser extent load. For a single phase fluid lubricant, entrainment is unimpeded. For a two-phase lubricant, such as PAO containing nanoparticles, whereby there are solid nanoparticles, entrainment could be modified depending on particle size, shape, and morphology. Such interference in fluid film lubrication can have an impact on the measured tribological performance of the lubricant. Furthermore, the shear behavior of a single fluid or a two-phase lubricant (liquid and solid) could be significantly different as was reflected in the friction and wear behavior. All these effects of fluid entrainment and interface shearing of lubricant fluid film are strongly dependent on the contact kinematics and the motion between the lubricated surfaces. Consequently, there would be differences between ball-on-flat and ring-on-liner reciprocating motion contact configurations, point and line contact, as observed in the present study.

Results presented in this work clearly illustrate the complexities of extrapolating results from simplified laboratory tribological testing to a complex component system. They also demonstrate the challenges of predicting the tribological performance of lubricants in real systems from simple benchtop tests. Using reciprocating motion, simply changing the contact configuration from a point (ball-on-flat) contact to a line (ring-on-liner) contact, coupled with changes in materials and surface morphology, resulted in significant changes in the friction and wear behavior of two lubricants containing nanoparticles. The ring-on-liner contact in the present study is certainly closer to the contact conditions in a real engine, especially at the TDC region. Hence, the test gives a better indication of engine performance with the four 


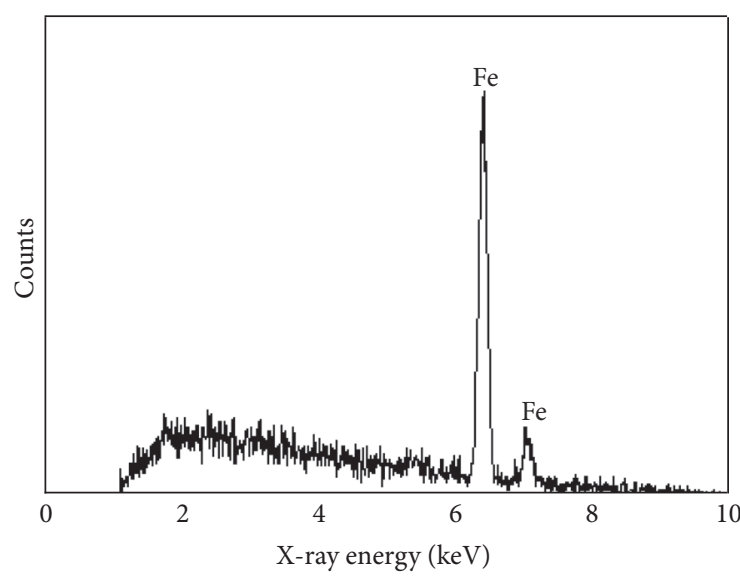

(a)

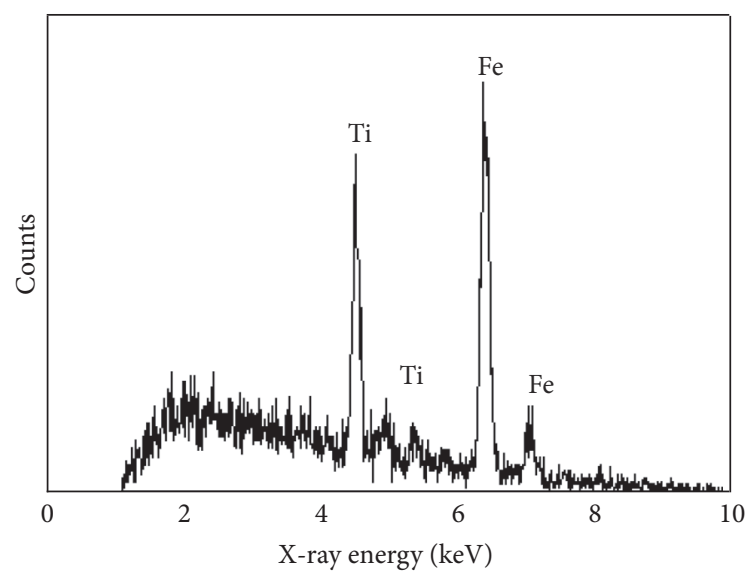

(c)

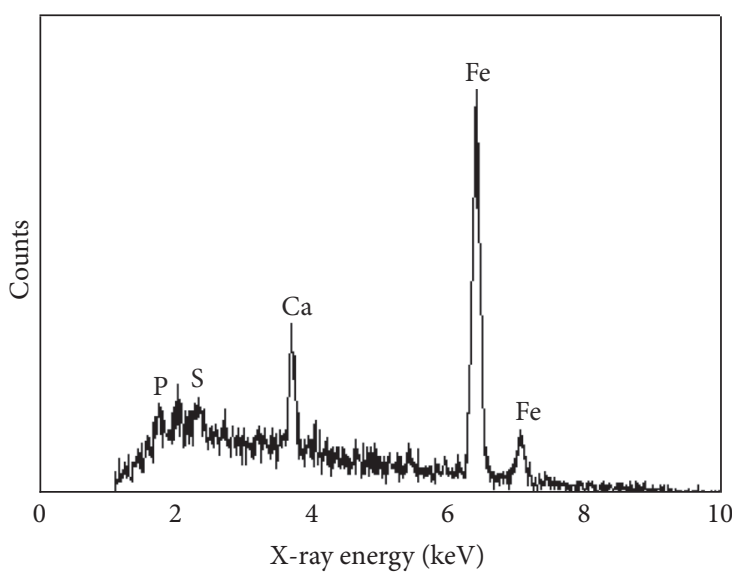

(b)

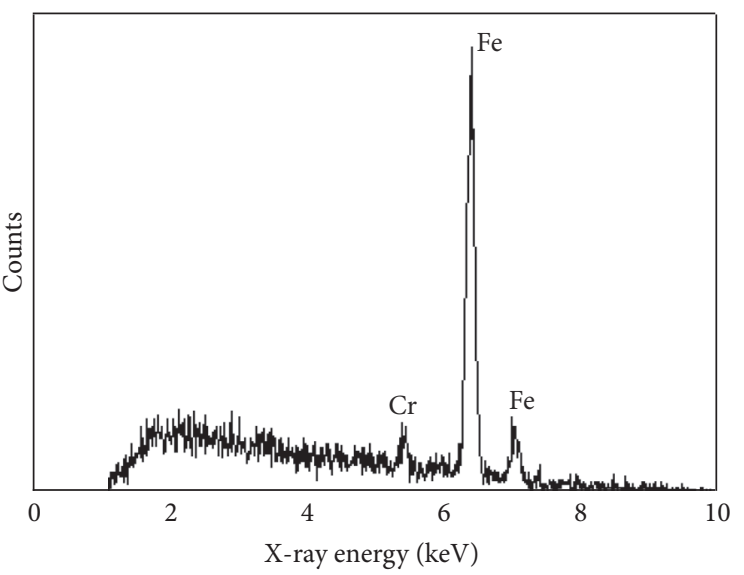

(d)

FIGURE 13: Energy dispersive X-ray spectra inside the flat test tracks for (a) PAO, (b) fully formulated 5W-30, (c) $\mathrm{PAO}+\mathrm{TiO}_{2}$, and (d) $\mathrm{PAO}$ $+\mathrm{Al}_{2} \mathrm{O}_{3}$.

lubricants evaluated. Minimal differences were observed in the friction and wear behavior in the ring-on-liner test, while more significant differences were observed in the ball-onflat configuration. Thus, a generalized conclusion about the efficacy of an additive in a lubricant based on the ball-on-flat test could be grossly misleading and no claims about the role of nanoparticles as additives in engine oil should be made without taking into account differences in tests geometry, contact pressures, metallurgy of test materials, and surface parameters.

\section{Conclusions}

Results from the ball-on-flat tests indicate reduced friction and wear by the addition of nanoparticles to base stock oil. During testing, $\mathrm{TiO}_{2}(5-10 \mathrm{~nm})$ nanoparticles in the oil were deposited onto the 52100 flat, and this condition led to the formation of a tribofilm above the surface, as examined by optical profilometry and EDX analysis. On the other hand, $\mathrm{Al}_{2} \mathrm{O}_{3}(5 \mathrm{~nm})$ nanoparticles in the oil were not deposited onto the 52100 flat, as revealed by EDX analysis and roughening of the surface occurred. However, during the ring-on-liner tests with the addition of nanoparticles, friction was not always lower than that of the base stock tests. The $\mathrm{TiO}_{2}$ and $\mathrm{Al}_{2} \mathrm{O}_{3}$ nanoparticles were both deposited onto the cast iron liner and severe abrasive wear, polishing, and pits were evident. Excessive wear of the liner that would result in excess oil consumption and blow-by would not be captured by a ball-on-flat test. Therefore, when testing solid oxide nanoparticles, the differences in test geometry, contact pressures, metallurgy of test materials, and surface parameters should be considered.

\section{Competing Interests}

The authors declare that they have no competing interests.

\section{Acknowledgments}

This work was supported by US Department of Energy, Energy Efficiency and Renewable Energy, Office of Vehicle Technologies, under Contract DE-AC02-06CH11357. The scanning electron microscopy was performed at the Electron Microscopy Center for Materials Research at Argonne 




(a)

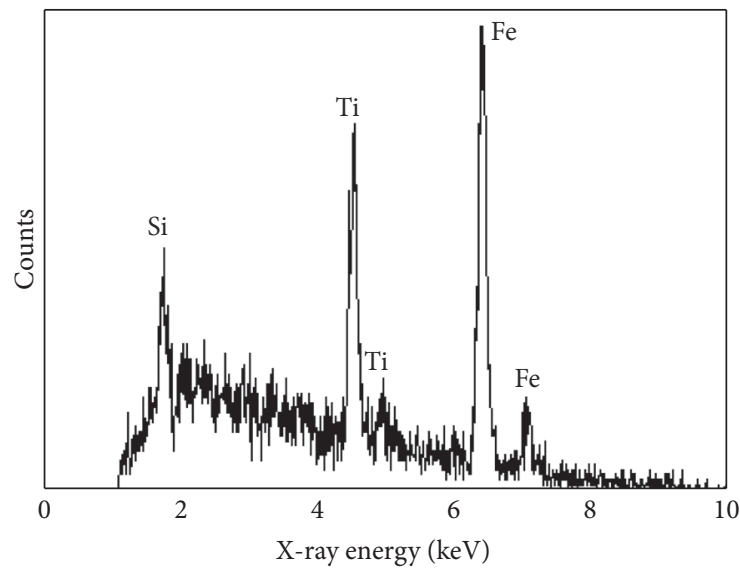

(c)

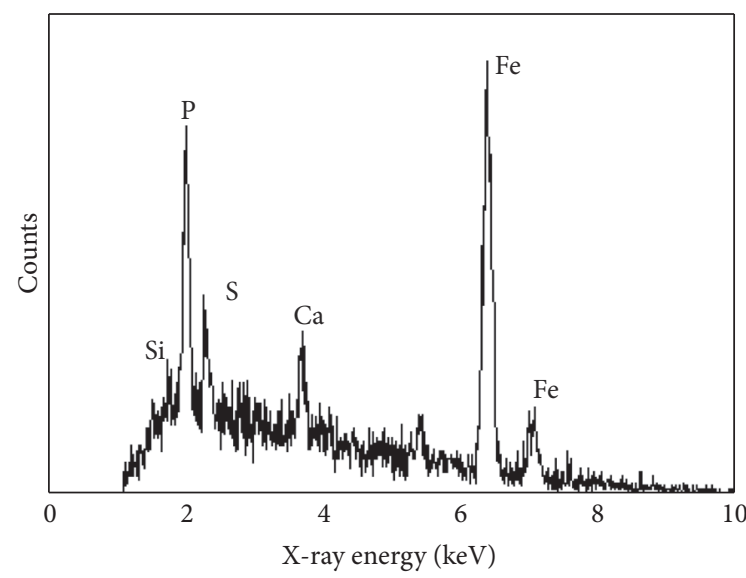

(b)

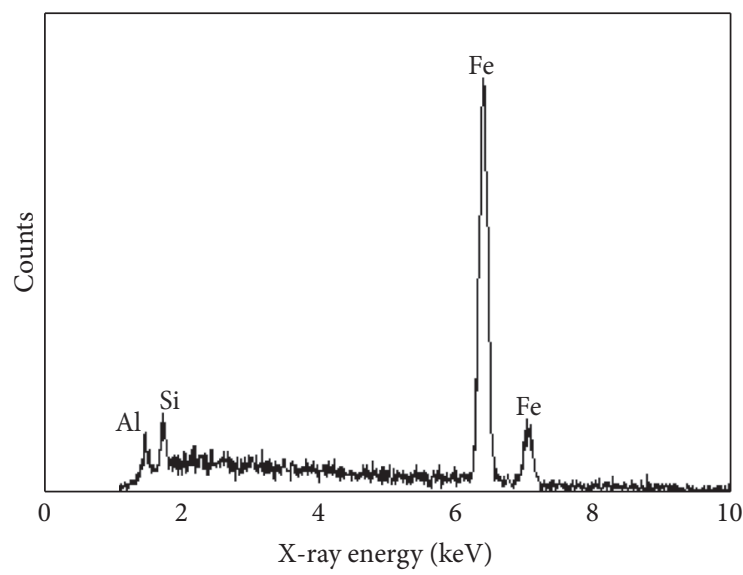

(d)

FIGURE 14: Energy dispersive X-ray spectra inside the test tracks on the cylinder liner segment for (a) PAO, (b) fully formulated 5W-30, (c) $\mathrm{PAO}+\mathrm{TiO}_{2}$, and (d) $\mathrm{PAO}+\mathrm{Al}_{2} \mathrm{O}_{3}$.

National Laboratory, a US Department of Energy Office of Science Laboratory operated by UChicago Argonne, LLC. The authors would like to acknowledge Eduardo Tomanik at Mahle Metal Leve SA for providing the piston ring and cylinder liner samples used in this work and Steven Kalberg for his help with the tribological testing.

\section{References}

[1] A. Hernández Battez, R. González, J. L. Viesca et al., "CuO, $\mathrm{ZrO}_{2}$ and $\mathrm{ZnO}$ nanoparticles as antiwear additive in oil lubricants," Wear, vol. 265, no. 3-4, pp. 422-428, 2008.

[2] X. Tao, Z. Jiazheng, and X. Kang, "The ball-bearing effect of diamond nanoparticles as an oil additive," Journal of Physics D: Applied Physics, vol. 29, no. 11, pp. 2932-2937, 1996.

[3] M. Ratoi, V. B. Niste, and J. Zekonyte, "WS 2 nanoparticlespotential replacement for ZDDP and friction modifier additives," RSC Advances, vol. 4, no. 41, pp. 21238-21245, 2014.

[4] B. A. Kheireddin, W. Lu, I.-C. Chen, and M. Akbulut, "Inorganic nanoparticle-based ionic liquid lubricants," Wear, vol. 303, no. 1-2, pp. 185-190, 2013.

[5] W. Ye, T. Cheng, Q. Ye, X. Guo, Z. Zhang, and H. Dang, "Preparation and tribological properties of tetrafluorobenzoic acid-modified $\mathrm{TiO}_{2}$ nanoparticles as lubricant additives," Materials Science and Engineering A, vol. 359, no. 1-2, pp. 82-85, 2003.

[6] C. C. Chou and S. H. Lee, "Rheological behavior and tribological performance of a nanodiamond-dispersed lubricant," Journal of Materials Processing Technology, vol. 201, no. 1-3, pp. $542-547,2008$

[7] L. Joly-Pottuz, N. Matsumoto, H. Kinoshita et al., "Diamondderived carbon onions as lubricant additives," Tribology International, vol. 41, no. 2, pp. 69-78, 2008.

[8] S. Tarasov, A. Kolubaev, S. Belyaev, M. Lerner, and F. Tepper, "Study of friction reduction by nanocopper additives to motor oil," Wear, vol. 252, no. 1-2, pp. 63-69, 2002.

[9] J. Lin, L. Wang, and G. Chen, "Modification of graphene platelets and their tribological properties as a lubricant additive," Tribology Letters, vol. 41, no. 1, pp. 209-215, 2011.

[10] Y. Y. Wu, W. C. Tsui, and T. C. Liu, "Experimental analysis of tribological properties of lubricating oils with nanoparticle additives," Wear, vol. 262, no. 7-8, pp. 819-825, 2007.

[11] R. Rosentsveig, A. Margolin, A. Gorodnev et al., "Synthesis of fullerene-like $\mathrm{MoS}_{2}$ nanoparticles and their tribological behavior," Journal of Materials Chemistry, vol. 19, no. 25, pp. 4368-4374, 2009. 
[12] K. T. Miklozic, T. Forbus, and H. A. Spikes, "Performance of friction modifiers on ZDDP-generated surfaces," Tribology Transactions, vol. 50, pp. 328-335, 2007.

[13] G. Liu, X. Li, B. Qin, D. Xing, Y. Guo, and R. Fan, "Investigation of the mending effect and mechanism of copper nano-particles on a tribologically stressed surface," Tribology Letters, vol. 17, no. 4, pp. 961-966, 2004. 

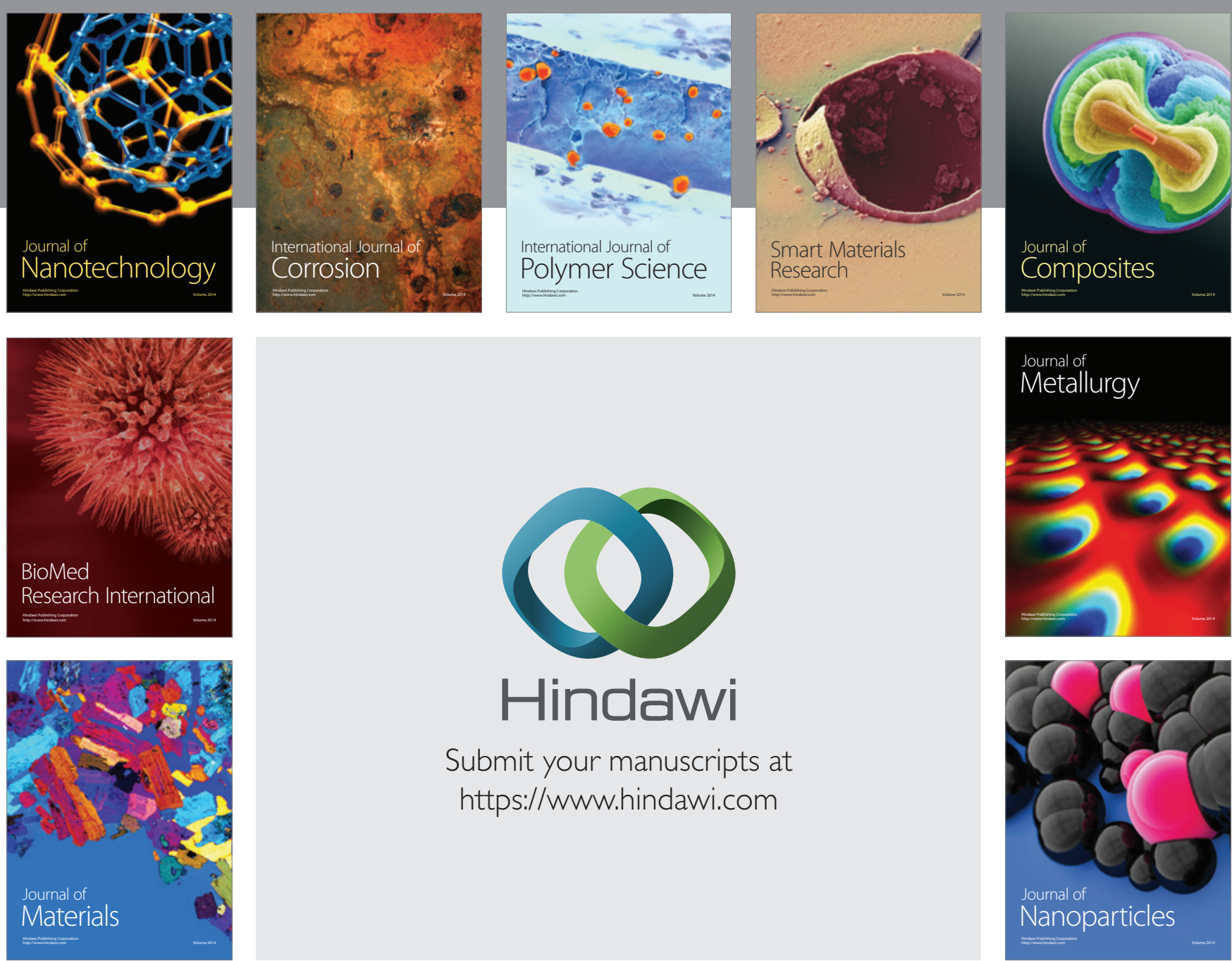

\section{Hindawi}

Submit your manuscripts at

https://www.hindawi.com

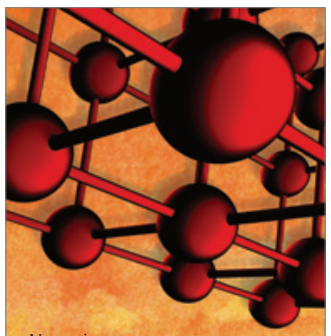

Materials Science and Engineering
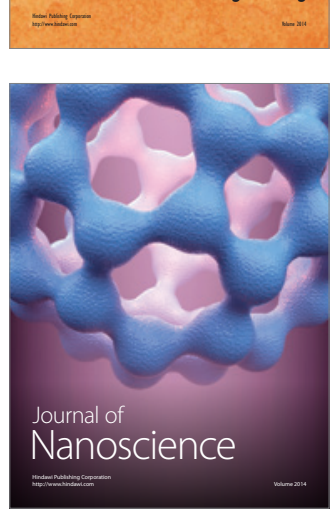
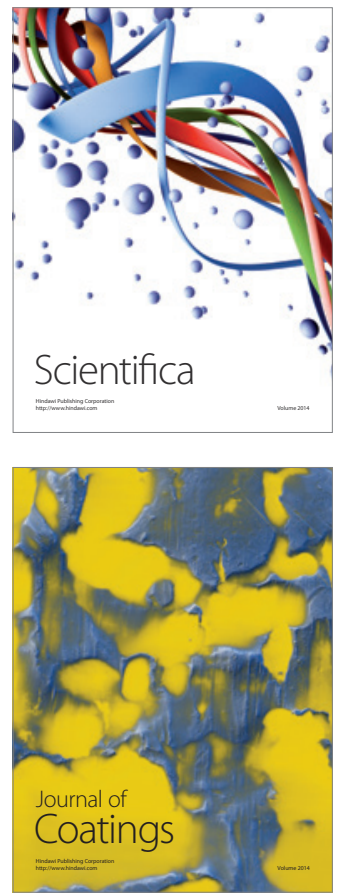
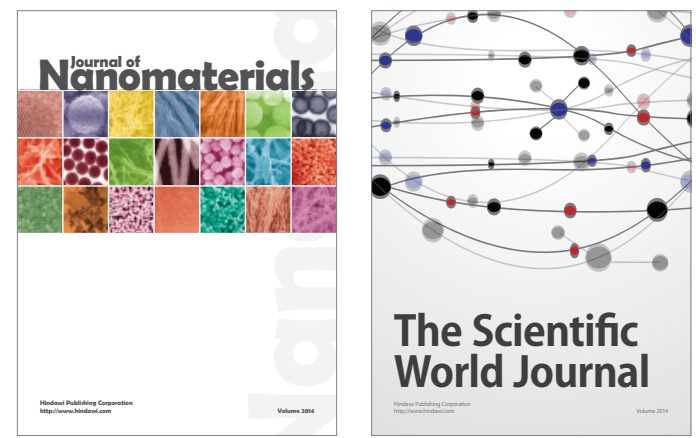

The Scientific World Journal
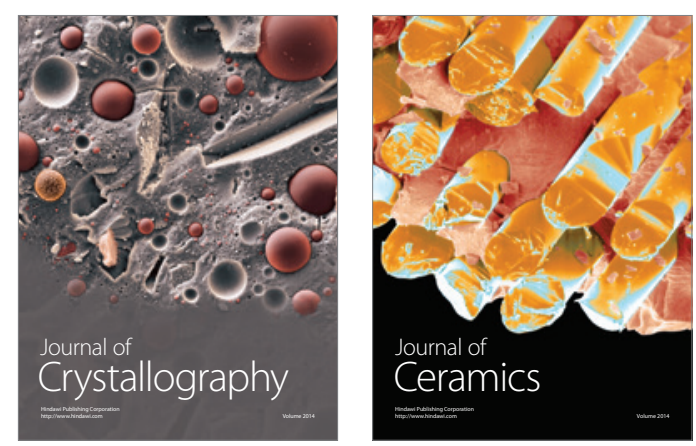
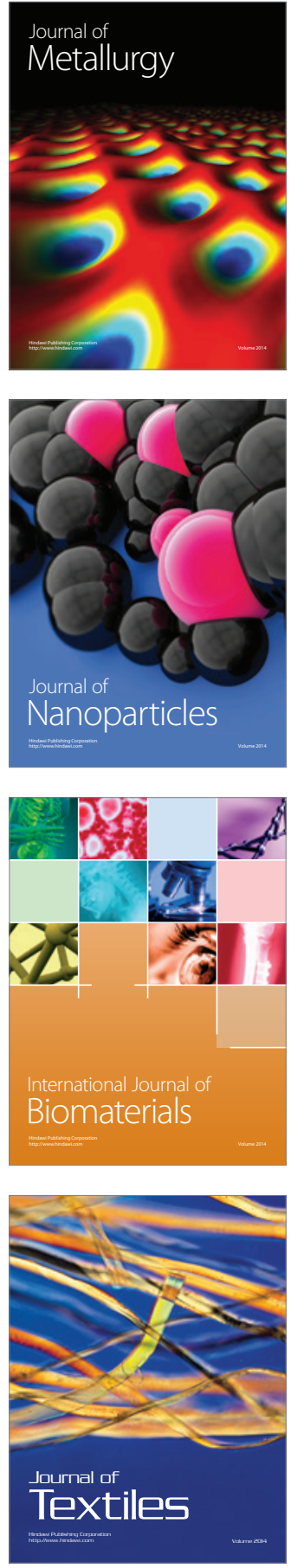